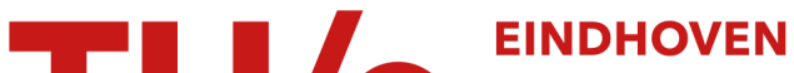 UNIVERSITY OF TECHNOLOGY
}

\section{Current interruption phenomena in HV disconnectors with high-speed opening auxiliary contacts}

\section{Citation for published version (APA):}

Chai, Y., Wouters, P. A. A. F., Kuivenhoven, S., Wal, van der, P., Vanis, M., \& Smeets, R. P. P. (2010). Current interruption phenomena in $\mathrm{HV}$ disconnectors with high-speed opening auxiliary contacts. In Proceedings of the 2010 IEEE Power and Energy Society General meeting, 25-29 July 2010, Minneapolis, Minnesota (pp. 1-8). Institute of Electrical and Electronics Engineers. https://doi.org/10.1109/PES.2010.5589651

DOI:

10.1109/PES.2010.5589651

Document status and date:

Published: 01/01/2010

\section{Document Version:}

Publisher's PDF, also known as Version of Record (includes final page, issue and volume numbers)

\section{Please check the document version of this publication:}

- A submitted manuscript is the version of the article upon submission and before peer-review. There can be important differences between the submitted version and the official published version of record. People interested in the research are advised to contact the author for the final version of the publication, or visit the $\mathrm{DOI}$ to the publisher's website.

- The final author version and the galley proof are versions of the publication after peer review.

- The final published version features the final layout of the paper including the volume, issue and page numbers.

Link to publication

\section{General rights}

Copyright and moral rights for the publications made accessible in the public portal are retained by the authors and/or other copyright owners and it is a condition of accessing publications that users recognise and abide by the legal requirements associated with these rights.

- Users may download and print one copy of any publication from the public portal for the purpose of private study or research.

- You may not further distribute the material or use it for any profit-making activity or commercial gain

- You may freely distribute the URL identifying the publication in the public portal.

If the publication is distributed under the terms of Article $25 \mathrm{fa}$ of the Dutch Copyright Act, indicated by the "Taverne" license above, please follow below link for the End User Agreement:

www.tue.nl/taverne

Take down policy

If you believe that this document breaches copyright please contact us at:

openaccess@tue.nl

providing details and we will investigate your claim. 


\title{
Current Interruption Phenomena in HV Disconnectors with High-Speed Opening Auxiliary Contacts
}

\author{
Y. Chai, P.A.A.F. Wouters, S. Kuivenhoven, P. van der Wal, M. Vanis, R.P.P. Smeets, Fellow, IEEE
}

\begin{abstract}
High-speed opening auxiliary contacts ("whip type device") is used to enhance the capacitive current interruption capability of air-break disconnectors. Firstly the paper introduces the basic working principle of this device. Secondly a series of laboratory tests are described. The voltages at both sides of the disconnector and the current through the disconnector are measured. The arc images are recorded by a high-speed camera with 1000 frames/s as well. The test data and arc images are studied for both failed- and successful interruptions. Finally, conclusions and remarks are given.
\end{abstract}

Index Terms--Arc, capacitive current, disconnector, high voltage, current interruption, re-ignition, test, whip-type, testing.

\section{INTRODUCTION}

$\mathrm{T}_{\mathrm{s}}$ O allow an air-break disconnector (also called Disconnect Switch: DS) to interrupt certain currents, several auxiliary devices such as arcing horns, vacuum interrupters, $\mathrm{SF}_{6}$ interrupters can be employed to reduce the effects and the duration of the arcs drawn during opening. In the early 1950s, a high-speed opening auxiliary contacts device called whip-type interrupter, attached to the blades of a disconnector, was introduced. According to the references [1]-[9] a high-velocity whip with spring interrupter has the potential to greatly reduce the arcing time. For instance, whip-type devices were reported and used successfully to drop $32 \mathrm{~km}$ of a $138 \mathrm{kV}$ line and 17 $\mathrm{km}$ of a $115 \mathrm{kV}$ line [1], [7], [9]. This device achieves a large gap in a very short time when the whip releases. It is currently used in North America to interrupt small capacitive currents, and also transformer magnetizing currents. It can be installed on any type of disconnector and in any mounting position [2]. The basic principle is: while the disconnector blades open, the whip springs remain in contact until the blades are some distance apart. Then, the whip is released, and its swing extinguishes the arc rapidly, mainly because a large gap is

Y. Chai, P.A.A.F. Wouters and R.P.P. Smeets are with the Electrical Power Systems Group, Department of Electrical Engineering, Eindhoven University of Technology, $5600 \mathrm{MB}$ Eindhoven, the Netherlands.

(Email: y.chai@tue.nl; p.a.a.f.wouters@tue.nl)

R.P.P. Smeets, S. Kuivenhoven are with KEMA T\&D Testing Services, Arnhem, the Netherlands.

(Email: rene.smeets@kema.com; sander.kuivenhoven@kema.com)

M. Vanis is with High Power Testing Laboratory, Podnikatelska 54719011 Praha 9, Czech Republic. (Email: vanis@zku.cz)

P. van der Wal is with HAPAM B.V.Voltaweg 30, 3752 LP, Bunschoten, the Netherlands.(Email: p.vanderwal@hapam.nl) reached in a very short time. The operating steps for the centerbreak disconnector with whip are shown in Fig.1.

- Step 1, with the disconnector closed the current flows through the main blades. The whip is not a part of the circuit.

- Step 2, as the disconnector blades start to open, the whip is moving. The left part of the whip is connected with the right part of the whip through a hook. The current flow is established through the left disconnector blade, the whip, and the hook.

- Step 3, as the blades continue to open, the mechanical energy is stored in the whip because of its spring nature. The whip is released at a certain point and the left part of the whip moves away from the hook. In the mean time, there is an arc between the hook and the tip of the whip.

- Step 4, due to the energy stored in the spring, the whip is released with a very high velocity; a large open air gap can be established between the tips of the whip rapidly and consequently between the main blades. The circuit is interrupted and a visible separation is provided.

It was found that high tip speed of quick-break devices significantly increase the interruption capability of a capacitive current. Assuming the arc reignites at the highest TRV and continues to burn at maximum for another half cycle $\left(T_{1 / 2}\right)$ to extinguish completely at the next current zero crossing, the arc duration $T_{a r c}$ can be estimated roughly with:

$T_{\text {arc }}=\frac{2.2 \sqrt{2} U_{s}}{v_{\text {air }} E}+T_{1 / 2}$

Here $v_{\text {air }}$ is the opening velocity of the air gap; $E$ is the air withstand electrical field; and $U_{s}$ is the system phase voltage. To allow for some margin, the system voltage is taken to be at $1.1 \mathrm{pu}$ and thus the recovery voltage peak of $2.2 \mathrm{pu}$ is applicable, which means that the maximal TRV (Transient Recovery Voltage) the circuit can offer is $2.2 \sqrt{2} U_{s}$ [4].

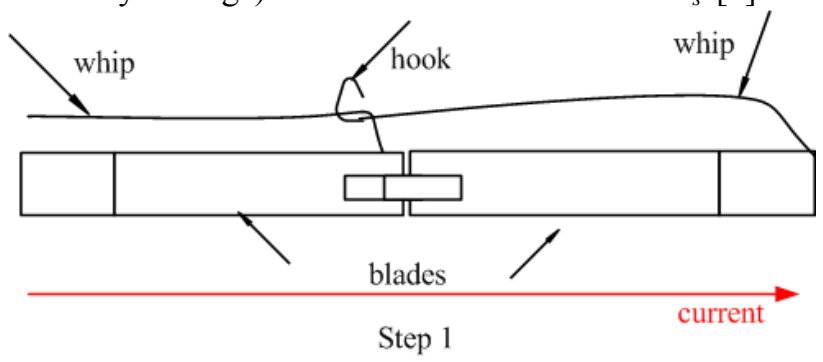



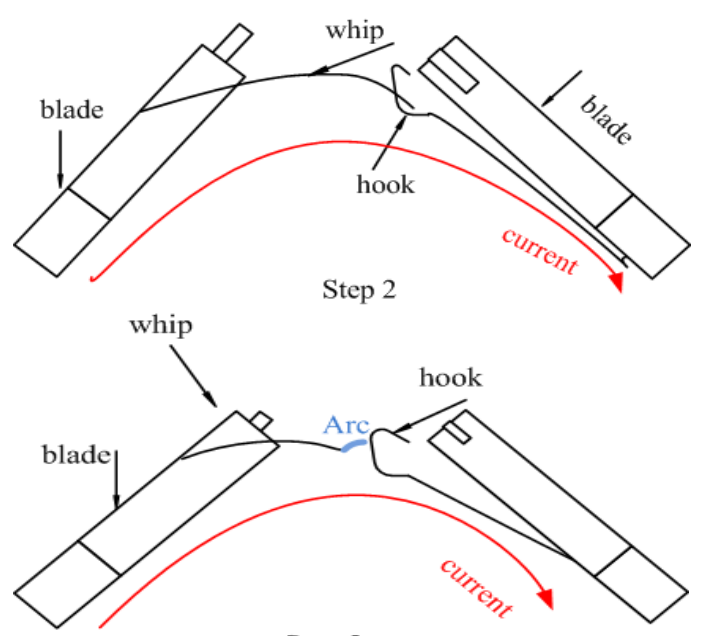

Step 3

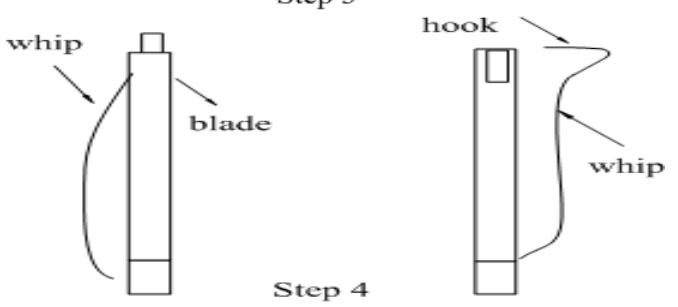

Fig. 1. Steps showing operating principle of a disconnector with whip.

Equation (1) shows that the larger $E$ and $v_{\text {air }}$ are and the lower $U_{s}$ is, the shorter the arc duration is. The whip should be released as fast as possible with little bounce. The breakdown field strength $E$ is affected by many factors, such as thermal effects from the arc current, blade geometry, air parameters, and so forth.

As mentioned before, there are several publications on this topic. However, there is little information on the interruption phenomena, such as the behavior of the arc on interruption. In order to test the interruption capability of a center-break disconnector (manufacturer HAPAM) for capacitive current and to investigate the phenomena, a series of tests is done at the ZKU High Power Laboratory (HPL), Prague.

\section{TEST SET-UP}

During the tests, the average relative humidity was $59 \%$, temperature $22^{\circ} \mathrm{C}$ and sunny weather conditions. Tests were performed in a test-cell that had one side facing the open air, excluding strong wind.

According to the newest IEC technical report [10], firstly $C_{s} / C_{\mathrm{l}}=28 / 320 \mathrm{nF}$ is selected; the current to be interrupted $I_{d}$ is about $10 \mathrm{~A}$ and the system supply voltage $U_{s}$ is $104 \mathrm{kV}$. Secondly $C_{s} / C_{1}=25 / 220 \mathrm{nF}$ is selected, the current $I_{d}$ is around $7 \mathrm{~A}$ with $104 \mathrm{kV} U_{s}$. Two voltage dividers with ratios of 2000 $\mathrm{V} / \mathrm{V}$ are used. The current is measured using Pearson Current Transformers (CT) with $0.05 \mathrm{~V} / \mathrm{A}$ sensitivity. The source side voltage $u_{c s}$, load side voltage $u_{c l}$, the current through the disconnector $i_{d p}$ (the current at power frequency) and $i_{d h}$ (the current at high frequency) are recorded by a Nicolet Genesis Digital System using isolated digitizers. A high-speed camera with speed of $1000 \mathrm{frames} / \mathrm{s}$ is used to record arc images. The
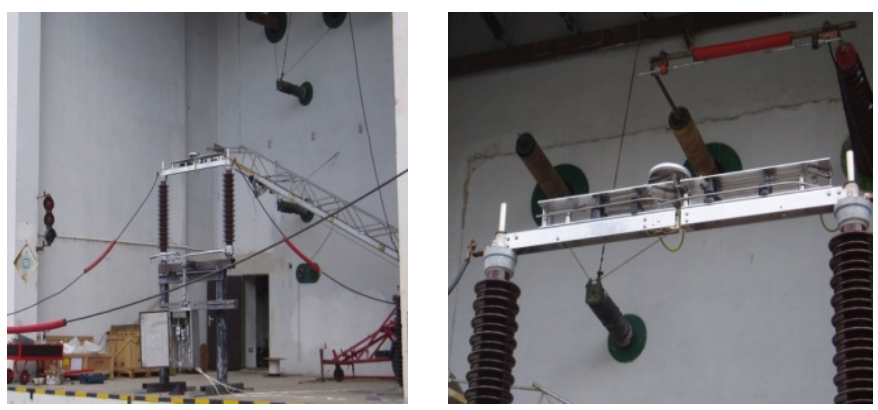

Fig. 2. Laboratory test set-up in ZKU HPL, Prague: general overview and disconnector blades with whip device.

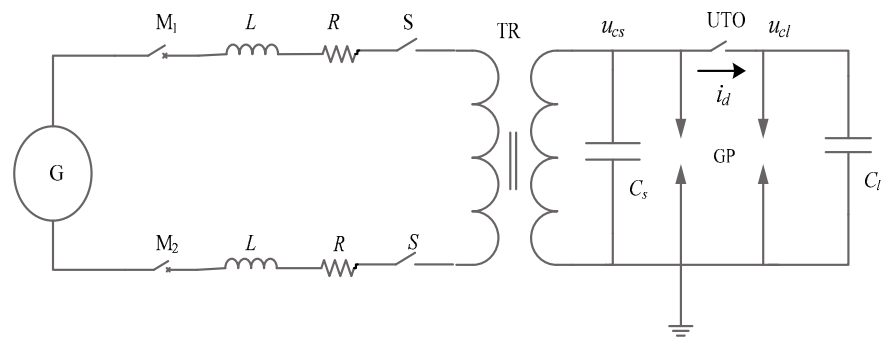

Fig. 3. Equivalent test circuit. G: short-circuit generator; $\mathrm{M}_{1}, \mathrm{M}_{2}$ : master breaker; $L, R$ : reactors and resistors from the source side; S: make switch; TR: short circuit transformer; $C_{s}, C_{l}$ : source side and load side capacitors bank; GP: air gap for protection; UTO: disconnector under test.

type of the disconnector to be tested is center-break, with rated voltage of $145 \mathrm{kV}$. The distance between two supporting insulators is $1650 \mathrm{~mm}$. The ratings for normal current and short circuit current are $1600 \mathrm{~A}, 80 \mathrm{kA}$ peak respectively. The laboratory test set-up is shown in Fig. 2. A simplified equivalent circuit for the test is shown in Fig. 3. The total number of full tests in the two series is 33 .

In the first series, the current to be interrupted $I_{d}$ ranges between $9.0-9.9 \mathrm{~A}$, one out of six performed tests failed. A failed test means the arc is not able to extinguish by itself before the blades of the disconnector are completely opened. On the contrary, a successful test means the arc manages to extinguish itself before the main blades are fully open. In the second series, the current to be interrupted $I_{d}$ ranges between 6.1 - 6.9A. One out of 27 performed tests failed.

The tests consisted of repeated close-open operations, however, only the open procedure is described in this paper. The arcs were either straight between the two tips of the whip contacts for successful tests or erratic in the air rooting at the main blades of the disconnector for failed tests. There are always re-ignitions, either by thermal or by dielectric breakdown. In order to explain these phenomena failed tests and successful tests are discussed separately.

\section{FAILED TESTS ANALYSIS}

There were two failed tests, one in the series with $I_{d}=9.0-$ 9.9A and another one in the series with $I_{d}=6.1-6.9 \mathrm{~A}$. After studying the measured data from these failed tests, it was found that the two processes of attempted interruptions behaved similarly. Therefore, only the failed test with interrupted current $I_{d}=9.3 \mathrm{~A}$ is described below. 


\section{A. Analysis Electrical Signals}

Fig. 4 shows the wave shapes of the voltage $u_{d}\left(=u_{c s}-u_{c l}\right)$ across the blades of the disconnector and the current $i_{d}$ through the whip. The interruption process starts at $P_{1}($ time $\mathrm{t}=0)$ and ends at $P_{3}$ (time $\mathrm{t}=800 \mathrm{~ms}$ ), where the laboratory master breaker interrupts the current. There is an arc after the tips of the whip are separated (time $P_{l}$ ).

In order to understand the process two phases (Phase I and Phase II) and a critical point $P_{2}$ are distinguished.

- Phase I $\left(P_{1}-P_{2}\right)$

In this period the arc, which lasts 3 cycles, starts at $P_{1}$ and ends at $P_{12}$. The arc reignites at each half cycle. The re-ignition voltages are relatively low (less than $20 \mathrm{kV}$ ) and the disconnector current has obvious zero periods (see Fig. 4b), which also means the arc stops temporarily and then re-ignites once in each half cycle.

- Critical point $P_{2}$

The arc extincts temporarily at $P_{12}$. However, there is a very high re-ignition voltage of $287 \mathrm{kV}$ breaking down the air gap at time $P_{2}$. This re-ignition voltage is close to the maximum TRV of $294 \mathrm{kV}\left(2 \sqrt{ } 2 U_{s}\right)$ [4]. The arc reignites again at this point. Due to the source and load side capacitors' charge equalization [11], a high-frequency current of 220A is observed (Fig. 4d), but overvoltages across load- and source side capacitors are not observed.

- Phase II $\left(P_{2}-P_{3}\right)$

After the critical point $P_{2}$, the arc is re-installed between the main blades (not between the whip contacts) until it is interrupted finally by the master breaker. Fig. 4(a) shows that the arc lasts about $800 \mathrm{~ms}$ before the master breaker interrupts. Fig. $4 \mathrm{c}$ is an expansion in the period $P_{2}-P_{3}$ at $\mathrm{t}=220-225 \mathrm{~ms}$. Obvious arc current zero periods cannot be observed and the arc burns continuously without a measurable voltage to reignite, implying thermal re-ignition after every current zero. Fig. 4a also shows that the arc voltage is increasing gradually, from a few $\mathrm{kV}$ at the beginning up to $30 \mathrm{kV}$ in the end. The arc current and voltage are in phase which implies that the arc has a resistive nature. The arc voltage increases with the increase of the arc length [4].

\section{B. Image Analysis}

The images show that the arc is almost straight between two tips of the whip in Phase I (a typical arc image shown in Fig. 5). It can be observed clearly that the arc re-ignites and extinguishes each half cycle through intensity differences of arc brightness. The arc is moving upwards and is continuously burning at Phase II (a typical arc image is shown in Fig. 6). In order to show the arc position as a function of time, a two dimensional arc representation is given. Position " 0 " is the top of the left insulator; $D$ is the horizontal distance from the left insulator to the right insulator; height $H$ starts from the root of disconnector blades (see Fig. 6).
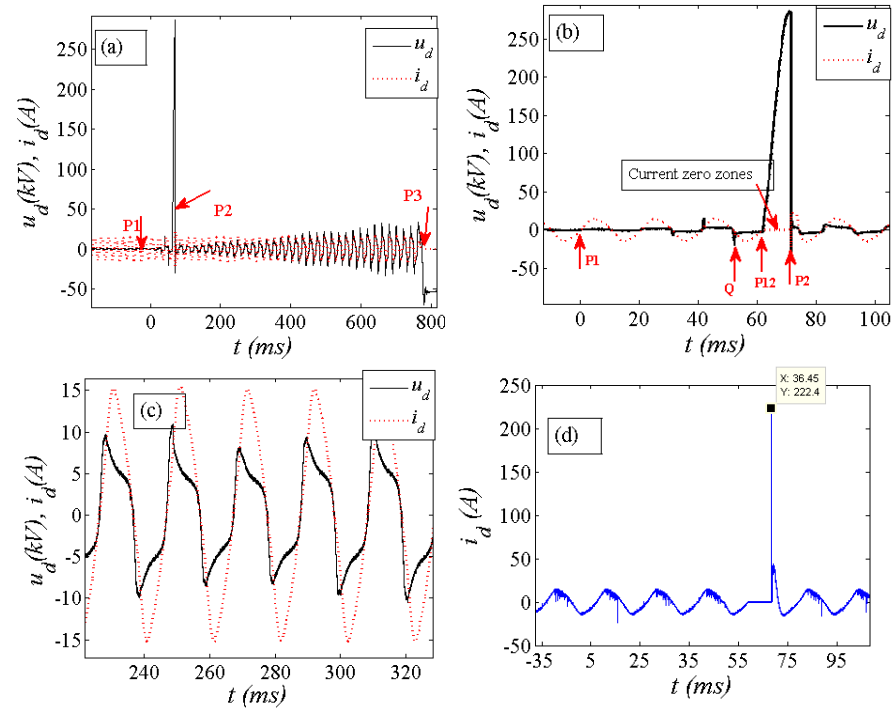

Fig. 4. (a) Wave shapes of the voltage $u_{d}$ and the current $i_{d}$, (b) their expansion at $t=0-100 \mathrm{~ms}$, (c) at $t=220-325 \mathrm{~ms}$ and (d) $i_{d}$ at $P_{2} . t=0$ is the moment when the two tips of the whip are released from each other $\left(I_{d}=9.3 \mathrm{~A}\right.$, failed interruption).

\section{- Phase I}

Since the arc burns straight between the tips of the whip in Phase I, the arc varies only in length (horizontally) but not in height (vertically).

Seven frames are selected in Fig. 7 upon re-ignition from each half cycle in Phase I, where the time difference between two frames is $10 \mathrm{~ms}$. For clarity an offset is added between every plotted frame. Initially, the arc is short $(33 \mathrm{~mm})$ due to the short distance between the tips of the whip. It becomes longer with increasing tip distance and reaches about $660 \mathrm{~mm}$ in the last half cycle before $\mathrm{P}_{12}$. The whip opening velocity is deduced from the images and is shown in Fig. 8. The speed with which the whip tips separate increases gradually from $2 \mathrm{~m} / \mathrm{s}$ ( $1^{\text {st }}$ frame) to $18 \mathrm{~m} / \mathrm{s}$ ( $7^{\text {th }}$ frame), with an acceleration of about $300 \mathrm{~m} / \mathrm{s}^{2}$.

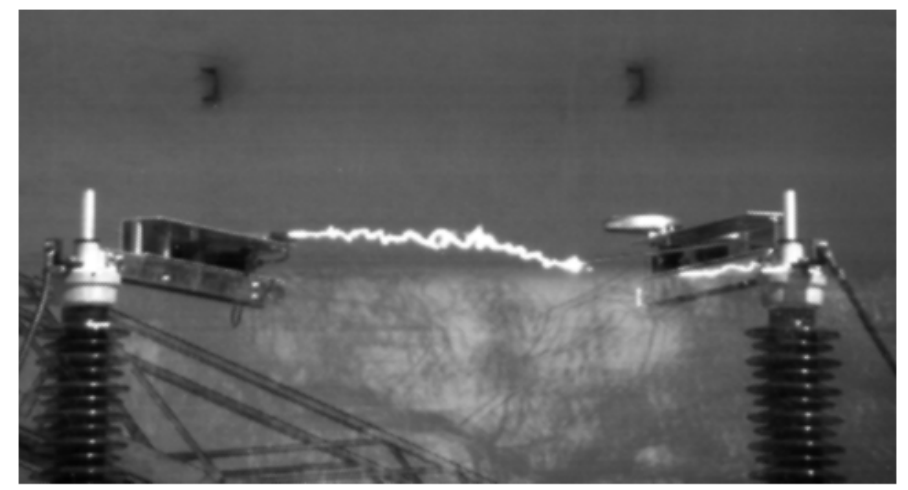

Fig. 5. A typical image of the arc in Phase I. 


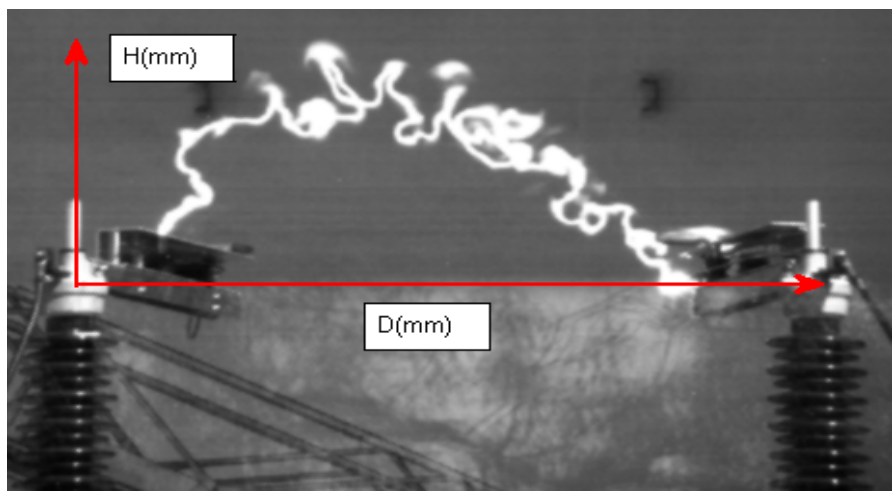

Fig. 6. Typical image of the arc in Phase II; the definition of arc height $(\mathrm{H})$ and $\operatorname{arc}$ reach $(\mathrm{D})$ is indicated.

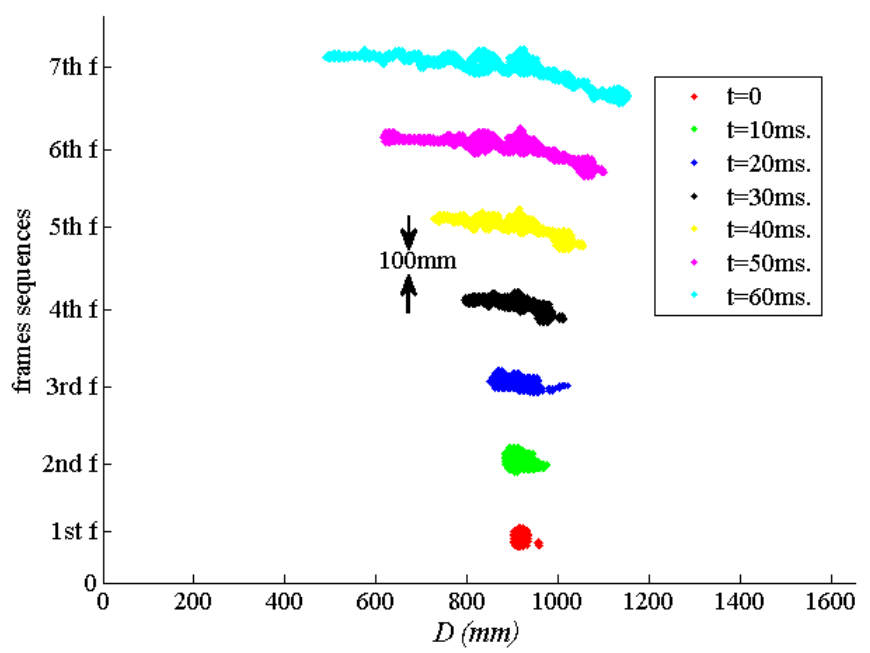

Fig. 7. Arc brightness pattern in period $P_{1}-P_{12}, H(\mathrm{~mm})$ for all arcs is $0 \mathrm{~mm} . D$ is the distance between two insulators $(1650 \mathrm{~mm}) ; D=0$ is the top the left insulator, see Fig.6.

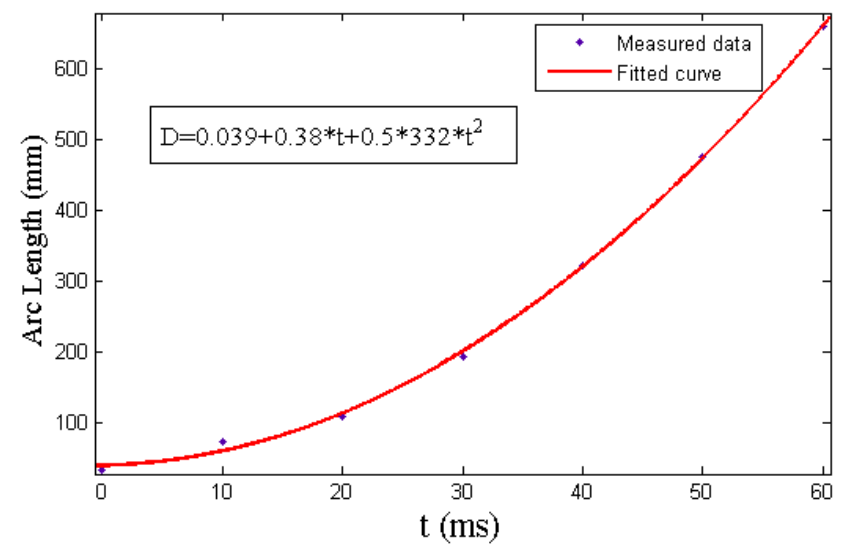

Fig. 8. The arc length versus time obtained from Fig. 7; the equation shows the distance as a function of velocity and acceleration.

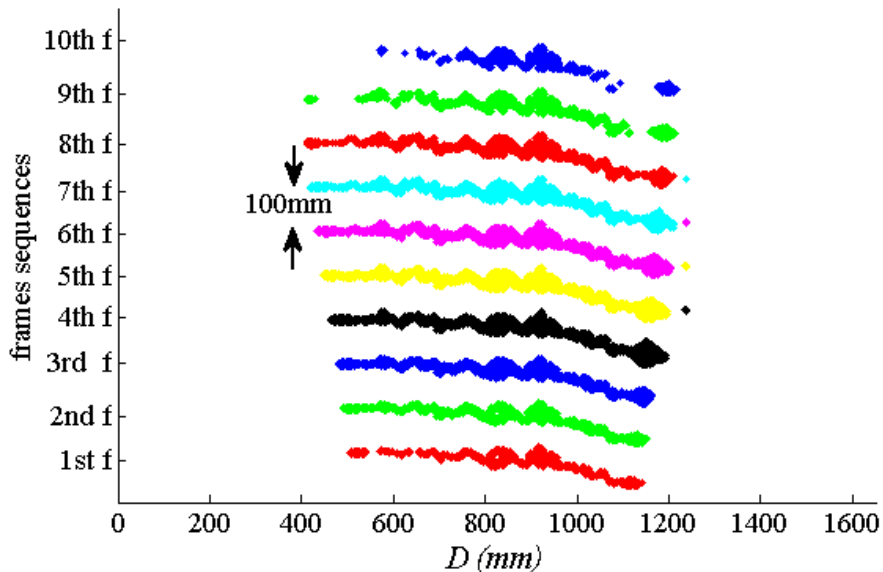

Fig.9. Ten subsequent images with $1 \mathrm{~ms}$ difference just before $P_{12}, \mathrm{H}(\mathrm{mm})$ for all arc curves is almost equal to zero. $\mathrm{D}(\mathrm{mm})$ indicates the distance in between the supporting insulators.

The arc motion within a half cycle in Phase I is shown in Fig. 9. A typical half cycle ending at $P_{12}$ in Fig. 4 is taken with a total number of ten frames (the time difference between two frames is $1 \mathrm{~ms}$ ). The curves are again visually separated by adding a vertical offset. It is observed that the intensity of arc is varying with current. It is strongest at the $5^{\text {th }}, 6^{\text {th }}$ or $7^{\text {th }}$ frame, where the arc current is close to its peak value. The arc length within this half cycle only increases slightly. It can be seen clearly that the highest brightness is in the centre of the arc, most distant from its footpoints.

\section{- Phase II}

Compared with the arc in Phase I, the arc in Phase II burns between two main blades, not between the whip tips; it is burning continuously, has a more arc-like shape and moves upwards. Fig. 10 shows the arc motion during $P_{2}-P_{3}$ of Phase II. It takes about 70 half cycles until the arc is interrupted by the master breaker. From each half cycle one frame is selected. Each sub-figure shows frames taken at corresponding phase angles for 10 subsequent half cycles; the seven sub-figures cover the complete arc duration. The time difference between two curves therefore is $10 \mathrm{~ms}$ and between two sub-figures is $100 \mathrm{~ms}$. The results show that the arc behaves erratic and moves upwards gradually; this is different from the straight arc in Fig. 7 and 9. The arc always follows the previous path which means the thermal behavior is the main effect. The last sub-figure in Fig.10 shows the moving speed of the highest point of the arc. It moves upwards with an almost constant velocity of $1.4 \mathrm{~m} / \mathrm{s}$.

The arc shape has not a perfect arc curvature but has several concave parts. These parts become deeper with increasing time. The deepest concave part is observed at the last subfigure. 

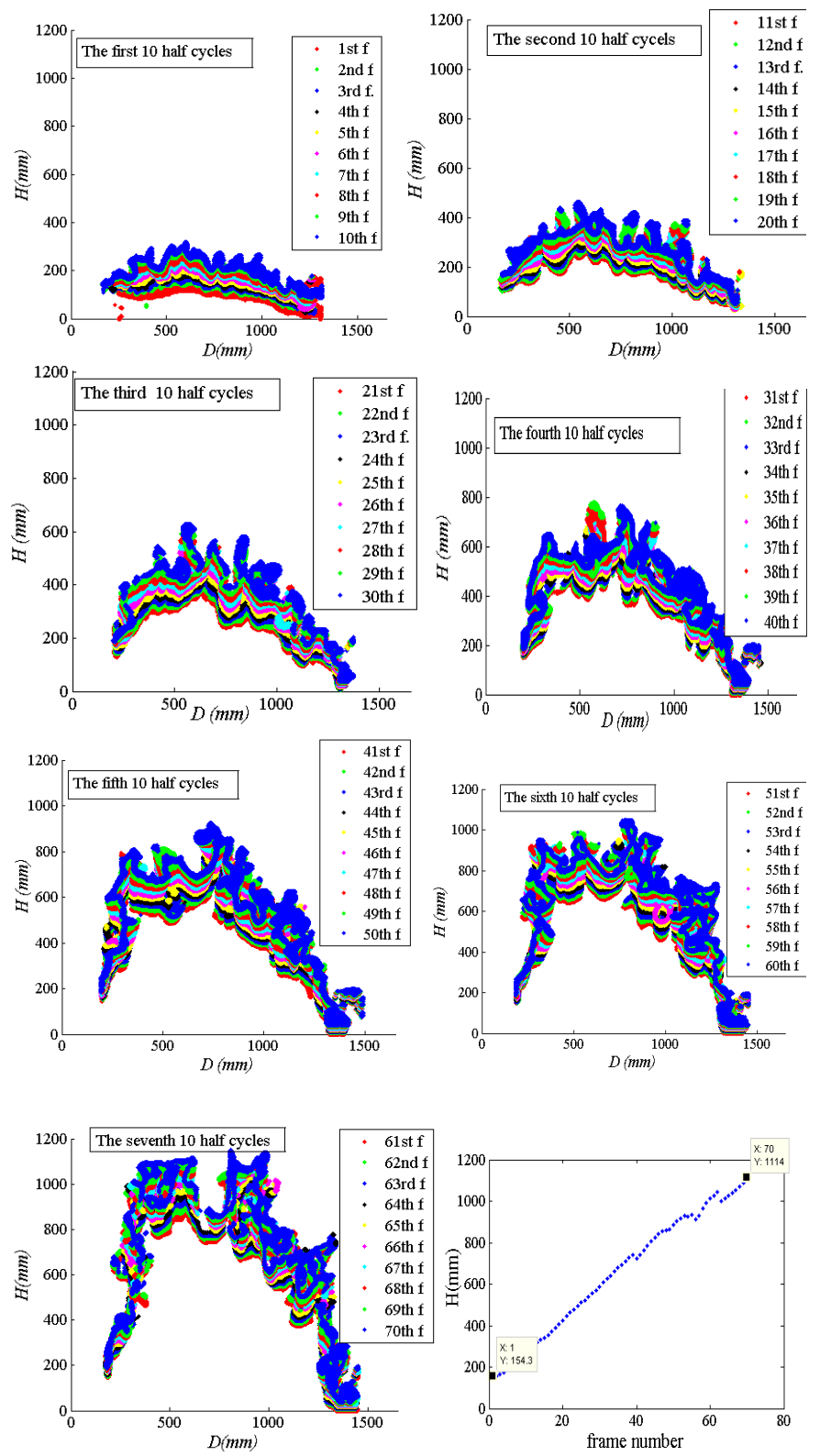

Fig. 10. Arc motion from $P_{2}-P_{3}$ and for highest vertical point the velocity versus frame number (frames are separated by $10 \mathrm{~ms}$ ).

A typical half cycle in Phase II, from $474 \mathrm{~ms}$ to $484 \mathrm{~ms}$, is selected for analysis. Ten frames separated by $1 \mathrm{~ms}$ difference are shown in Fig. 11.

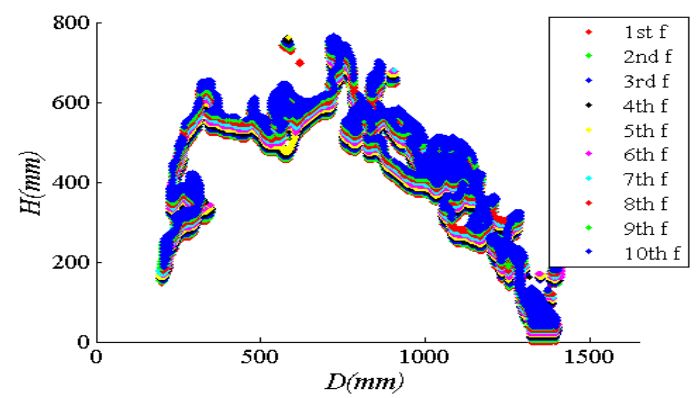

Fig. 11. Arc motion in a typical half cycle within the period of $P_{2}-P_{3}$.
The arc shape of these ten frames remains almost constant, while it is gradually moving upwards. The arc intensity difference between two successive frames is less obvious compared to Phase I. The $5^{\text {th }}, 6^{\text {th }}$ or $7^{\text {th }}$ (near current maximum) frames have higher intensity than the earlier frames.

Based on the results on failed interruptions the following conclusions are drawn:

- Capacitive current interruption with a whip disconnector causes a long arc between both tips of the whip firstly and main blades of the disconnector after the re-ignition. Initially, the arc is burning in a straight line between the whip contacts. After that, due to a high re-ignition voltage, the arc re-ignites between the main blades and it continues to burn and tends to move upwards.

- The failed interruption process includes two phases. In Phase I the arc re-ignites dielectrically and the re-ignition voltages are rather low (about 10-20kV). The arc current has obvious zero-periods at which it extincts temporarily and reignites regularly at each half cycle. The arc length in Phase I increase rapidly, determined by the whip gap elongation. In Phase II the arc re-ignites thermally, and burns continuously. The arc has no obvious current-zero periods. The arc voltage increases with the length of the arc (also arc reach) while moving upwards [4]. The highest vertical point of each arc is going upwards linearly. With a moving speed of about $1.4 \mathrm{~m} / \mathrm{s}$, the arc may easily endanger nearby electrical components of the network.

- After re-ignition, the arc path keeps following the path of the extinct arc both in Phase I and in Phase II. This implies that the thermal effect is a significant factor for the interruption, notably by reducing the breakdown in the hot trajectory of the just extinct arc.

- Within a half cycle, the arc light intensity depends on the (sinusoidal) arc current. It is highest at the peak value of the arc current. For an entire interruption progress, the highest arc intensity occurs at critical point $P_{2}$ where the re-ignition voltage is the highest. Apparently, the arc current and the reignition voltage are key factors which influence the arc intensity.

- There is a high re-ignition voltage which is close to the maximum TRV of circuit at the critical point between two phases; re-ignition from this voltage is a key problem which causes the arc to burn between the main blades. It is the main reason why the test failed.

\section{Successful Test Data Analyses}

In successful interruptions the arc normally lasts several tens of milliseconds. Fig. 12 shows the arcing time versus the interrupted current $I_{d}$. 


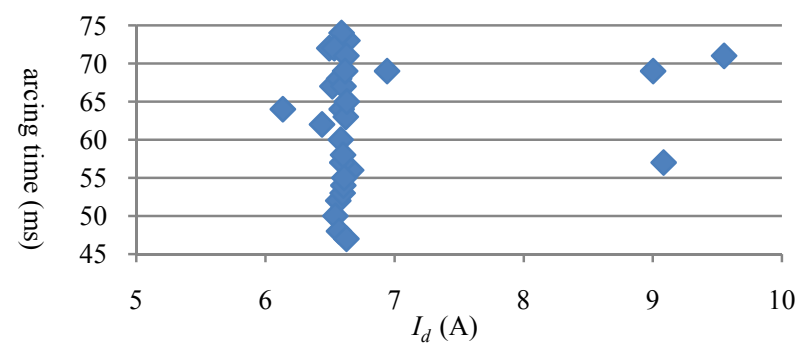

Fig. 12. Arcing time versus the interrupted current for successful tests.

Fig. 12 shows the arcing time spreads between $45 \mathrm{~ms}$ and $75 \mathrm{~ms}$. It is much shorter compared to the arcing time from an interruption using a disconnector without whip, where the arcing time normally lasts a few hundred milliseconds, and even can be up to several seconds [4], [11]. According to the tests, the arcing time does not appear to have a clear relationship with the interrupted current, at least for values up to 9A. Similar tests also show the arcing time ranges from $40 \mathrm{~ms}$ to $72 \mathrm{~ms}$ at $I_{d}=7.2 \mathrm{~A}$ [13]. This is different from a disconnector without whip, where the arcing time strongly depends on the interrupted current. This is related to the high opening speed compared to the main blades of a disconnector which move with a relatively low speed of typically $0.5 \mathrm{~m} / \mathrm{s}$.

Through careful study of all the measured data and images from the successful tests with current $I_{d}=6.1-6.9 \mathrm{~A}$, it is found that successful tests can be divided into three types of interruptions according to their final re-ignitions. Wave shapes for these currents $i_{d}$ and voltages $u_{d}$ across the tips for the three types of interruptions are shown in Fig. 13, 14 and 15 respectively.
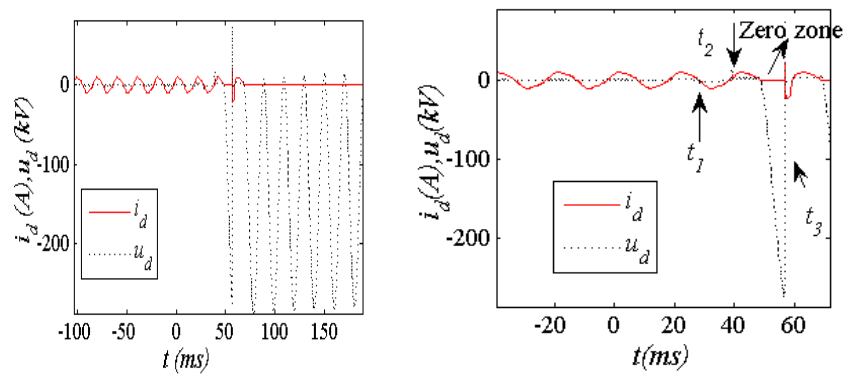

Fig. 13. Wave shapes of voltage $u_{d}$ and current $i_{d}$ and their expansion at $t=0$ $70 \mathrm{~ms}$, where $\mathrm{t}=0$ is the moment of whip release $\left(I_{d}=6.5 \mathrm{~A}\right)$, single dielectric re-ignition
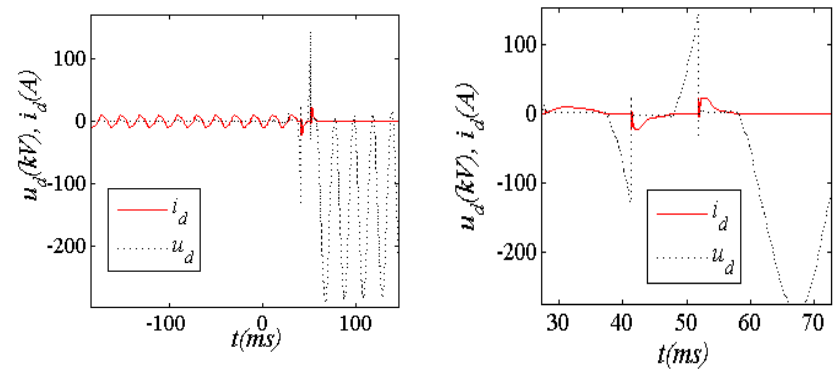

Fig. 14. Wave shapes of voltage $u_{d}$ and current $i_{d}$ and their expansion at $t=0$ $70 \mathrm{~ms}$, where $I_{d}=6.6 \mathrm{~A}$, double dielectric re-ignition.
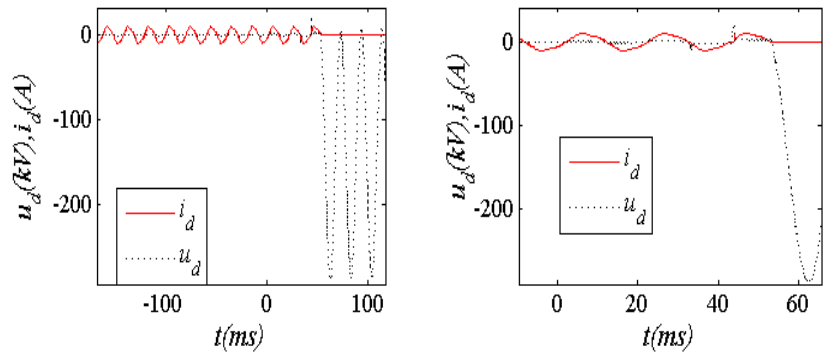

Fig. 15. Wave shapes of voltage $u_{d}$ and current $i_{d}$ and their expansion at $t=0$ $70 \mathrm{~ms}$, where $I_{d}=6.6 \mathrm{~A}$, no dielectric re-ignition.

Type I, typically as shown in Fig. 13, has only one very high final (dielectric) re-ignition voltage (see time $t_{3}$ ) with a value of more than $200 \mathrm{kV}$ occurring after several thermal reignitions, the re-ignition voltages of which are rather low, up to several tens $\mathrm{kV}$ (see $t_{1}$ and $t_{2}$ ). This type of interruption is observed in $60 \%$ of all successful tests. The range of the highest re-ignition voltages is from $200 \mathrm{kV}-289 \mathrm{kV}(1.4-2.0$ p.u), which is close to the maximum TRV. Also high reignition currents with values up to $531 \mathrm{~A}$ in these tests are observed at high frequency when the capacitor banks at both sides equalize upon re-ignition [11]. After the re-ignition at $t_{3}$, the arc extincts completely at the next current zero crossing and the interruption is successful. The arcing time of Type I is between $60 \mathrm{~ms}$ and $75 \mathrm{~ms}$ in this test.

The arc only burns between the tips of the whip and not between the main blades. This is a significant difference between failed tests and successful tests. The typical arc image for successful tests is shown in Fig. 5.

The arc motion within different half cycles before $t_{3}$ (Fig. 13) is analyzed. Five frames with time difference of $10 \mathrm{~ms}$, each of which is selected directly after re-ignition, are shown in Fig. 16. The vertical extension of the arc is again negligible. The arc length (horizontal) ranges from $33 \mathrm{~mm}$ to $370 \mathrm{~mm}$.

The arc motion after $t_{3}$ (re-ignition) to extinction is shown in Fig. 17. The arc intensity is strongest at the re-ignition moment and then becomes weaker. However, after $3-4$ frames, it becomes temporarily stronger and finally weaker again. That means the arc brightness does not only depend on energy input by the high-frequency current at re-ignition, but also on the arc power frequency current. This conclusion is similar as that drawn from study of the failed tests.

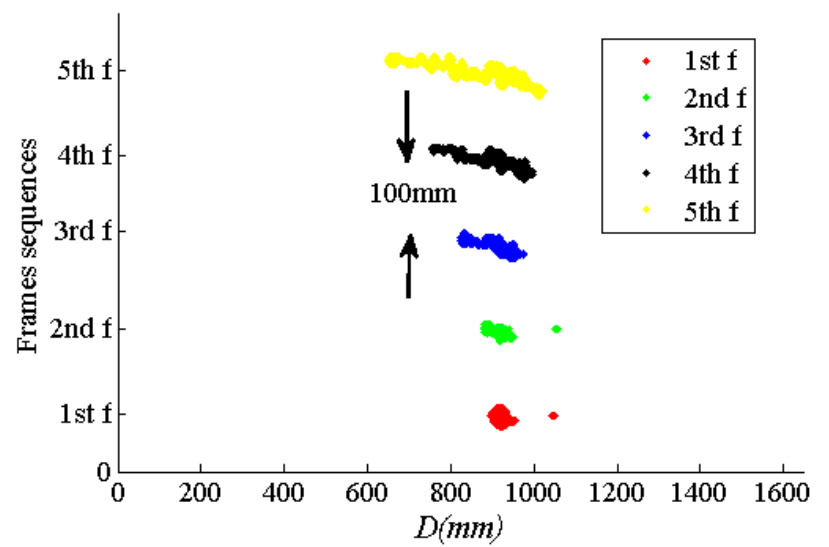

Fig. 16. Arc images and their corresponding lengths shown for 5 half cycles before $t_{3}$ in Fig. 13 


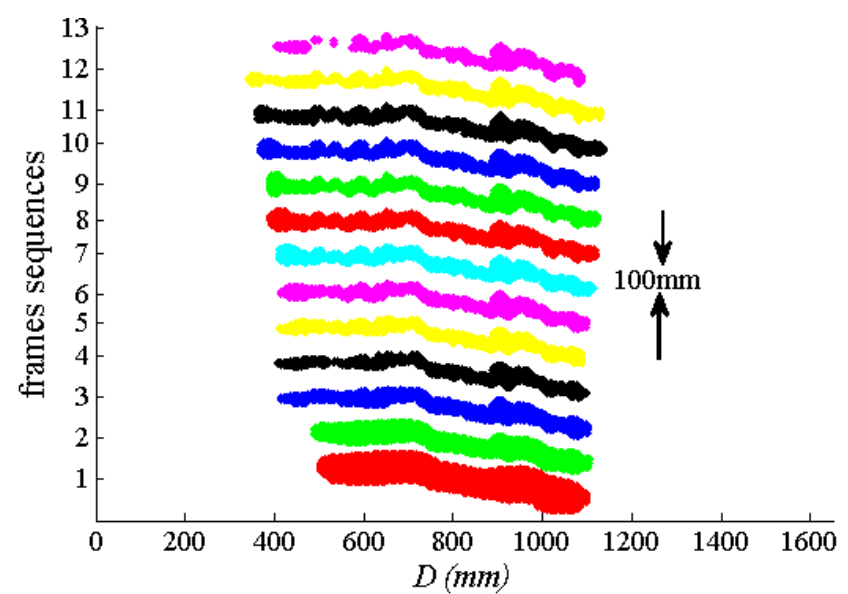

Fig. 17. Arc brightness after $t_{3}$ and its comparison in common axis; the time difference between the patterns is $10 \mathrm{~ms}$.

Type II interruption is shown in Fig. 14, where there are two re-ignitions with relatively low voltages TRV of $150-172 \mathrm{kV}$. These re-ignition voltages are about half of the maximum TRV the circuit supplied. This type interruption comprises about $10 \%$ of all tests. In the type II the re-ignition current is also high, but its value $(200-300 \mathrm{~A})$ is lower than the re-ignition current observed in Type I (300 - 500A). The arcing time in Type II is between $60 \mathrm{~ms}$ and $75 \mathrm{~ms}$ as well.

The arc images in Type II have similar characteristics as type I. The differences between arc Type I and Type II are the visual intensity and diameter of the arc column. The intensity of the arc at re-ignition from Type $\mathrm{I}$ is much higher than that from Type II. The diameter of the arc at re-ignition from Type I is much larger than that from Type II as well.

The typical wave shape of Type III is shown in Fig. 15. This type of interruption comprises $30 \%$ of the tests. In this type, no dielectric re-ignition is observed: the final (highest) re-ignition voltage remains in the thermal arc range and is a few tens of $\mathrm{kV}$. Most of re-ignition voltages are below $50 \mathrm{kV}$ and the arc duration is shorter than $60 \mathrm{~ms}$.

Fig. 18 shows the arc types upon each final re-ignition for Type I (a), Type II (b) and Type III (c) respectively. It can be observed that the intensity is brightest for Type I and weakest for Type III. The visible diameter of Type I (a), Type II (b) and Type III (c) is approximately $60 \mathrm{~mm}, 43 \mathrm{~mm}$ and $36 \mathrm{~mm}$ respectively.

Through the analysis of successful tests, the following conclusions are drawn.

- There are three types of successful interruptions. Type I, which occurs in $60 \%$ of the tests, has the largest re-ignition voltage almost up to $\left(2 \sqrt{2} U_{s}\right)$. A current up to $531 \mathrm{~A}$ is measured at re-ignition. The arc in Type I has the highest intensity and the largest diameter of the arc column.

- Type II, which comprises $10 \%$ of the tests, has also a large re-ignition voltage up to $170 \mathrm{kV}\left(\sqrt{ } 2 U_{s}\right)$ but significantly lower than that for Type I. A high current through the whip up to $300 \mathrm{~A}$ is caused, which is lower than that from Type I. The arc upon re-ignition has lower intensity and smaller diameter compared to Type I.
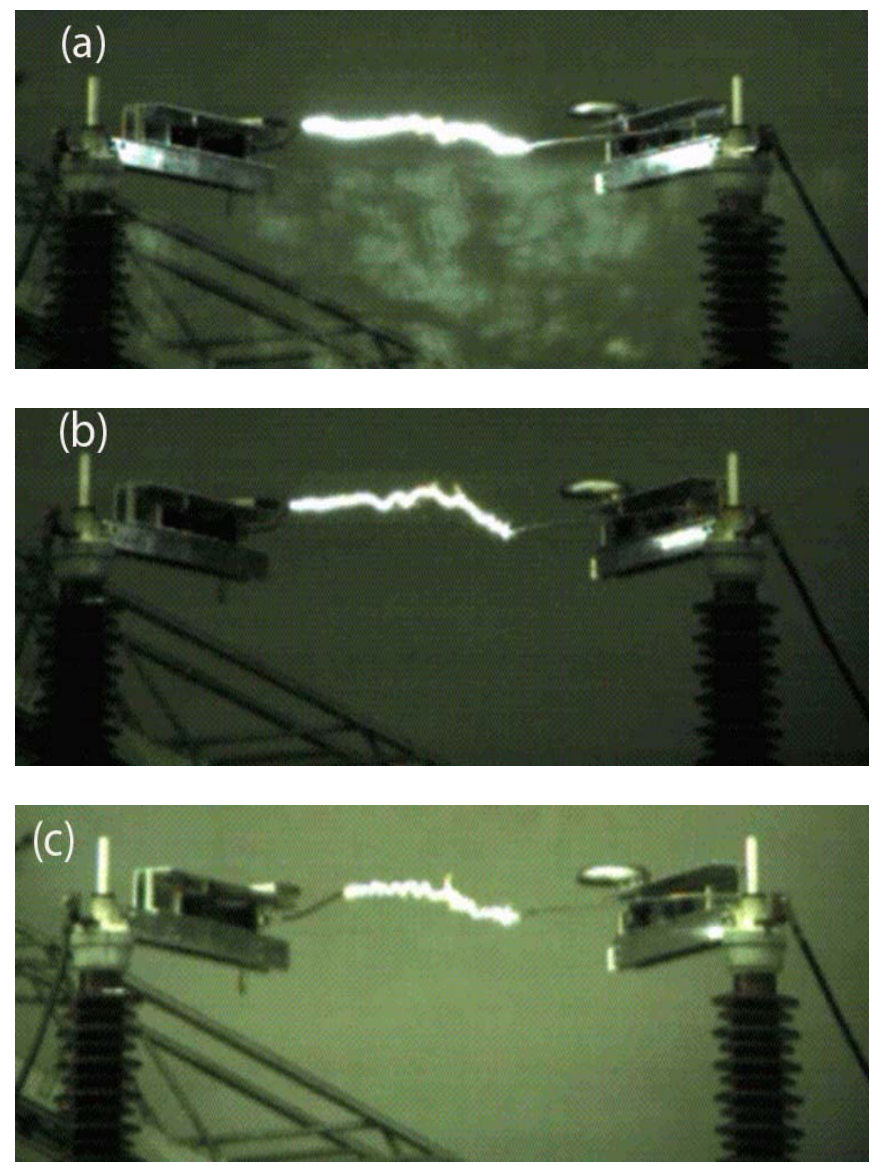

Fig. 18. Typical arc on re-ignition from (a)Type I, (b)Type II and (c) Type III respectively.

- Type III, which occupies $30 \%$ of the tests, has lowest maximal re-ignition voltage with a value up to $50 \mathrm{kV}$. There is no high re-ignition current observed. The intensity of the arc is weakest at the re-ignition and the arc has a smallest diameter compared to Type I and Type II interruption.

- The shapes of the arc are not straight lines between two tips, but bends several times near the middle part (see Fig.17, 18). The arc intensity and diameter are higher with larger reignition voltage and arc current.

- The arcing time is between $45 \mathrm{~ms}$ and $75 \mathrm{~ms}$, not clearly depending on the interrupted current magnitude for the current range in the test. However, the arcing time in Type I and Type II is over $60 \mathrm{~ms}$, which is longer than the arcing time from Type III.

\section{CONCLUSION AND DISCUSSION}

In this paper the capacitive current interruption process using a centre-break disconnector with a whip interrupter is studied in detail experimentally. The main conclusions are:

The arc starts to burn straight between tips of the whip once it is released. It remains straight and extincts completely if the air gap is large enough and there are no further re-ignitions before the whip is fully released. If the test fails, the arc reignites between the main blades and moves upwards rapidly. Experience show that once the arc reignites between the main blades, the interruption will fail.

The arc tries to keep the same path after each re-ignition, 
which means the arc always experiences the hot air as the easiest channel for re-ignition.

The arc brightness depends on the arc current and the reignition voltage. The higher re-ignition voltage and arc current are, the stronger the arc intensity is. The arc shapes between tips of the whip are almost straight with a slight bending; the shapes of arcs burning between two blades are curves with several concaves.

The length of the straight arc before the arc burns upwards depends only on the increasing air gap distance. That means the higher the whip separation speed is, the longer the arc is, and the faster the arc extincts, probably because of avoiding of accumulation of thermal energy that reduces re-ignition voltage.

The overvoltage by a disconnector interruption of capacitive currents is one of the main causes for over voltages in the network. A value of 2.5 p.u. was reported in literature [4]. However, there is no overvoltage across the capacitors observed in the tests in this study. A re-ignition current up to $531 \mathrm{~A}$ is found.

The test shows the whip is a very effective way to increase capability of the disconnector to interrupt the capacitive current since the arcing time is much shorter compared to the interruption by disconnector without whip. The moment that the whip releases, however, should be chosen such that dielectric re-ignition of the arc between the main blades is avoided.

Although much data are studied in this paper, it is still insufficient from statistical point of view. It is hard to find what the actual reasons are for tests to fail: possibly the whip was released before sufficient main blade gap was reached. There is no information on the bounce of whip (reduction of whip spacing after reaching the maximum gap length) as well, since a bounce of the whip is a vital factor affecting the interruption capability. More measurements with different whip types, whip settings and with different interrupted current are required.

\section{REFERENCES}

[1] S. G. Patel, W.F. Holcombe and D.E. Parr, "Application of air-break switches for de-energizing transmission lines," IEEE Trans. on Power Apparatus and Systems, vol. 4, pp368-374, Jan. 1987.

[2] David Childress, "Disconnect switch mounted interrupting devices how to choose what to use when and where", Available: www.southernstatesllc.com/pdf/MIPSYCON.pdf.

[3] John Douglas McDonald, Leonard L. Grigsby, Electric power substations engineering, Taylor and Francis Group, 4-1, 2007.

[4] D. F. Peelo, "Current interruption using high voltage air-break disconnectors". Ph.D. dissertation, Dept. Electrical Engineering, Eindhoven Univ. of Technology, Eindhoven, 2004.

[5] E. C. Rankin, "Experience with methods of extending the capability of high-voltage air break switches," AIEE Trans. on Power Apparatus and Systems, vol.78, pp.1634-1636, Dec. 1959.

[6] E. L. Luehring, J. P. Fitzgerald, "Switching the magnetizing current of large 345-kV transformers with double-Break air switches". IEEE Trans. on Power Apparatus and Systems, vol. pas-84, pp.902 - 906 Oct.1965.

[7] F.S. Toomer, "Switches of $115 \mathrm{kV}$ (Lines) updated as capacity", electrical world, Mar. 1965.

[8] BPA Division of Laboratories: Laboratory Report ELE-89-39, "Tests to determine the interrupting capabilities of $115 \mathrm{kV}$ quick break devices". March 1989.

[9] T.J. Jackson, "138 kV air switch interrupting device tests". Presented at PEA Electrical Equipment Meeting, Hershey, Pennsylvania, May 1977.
[10] IEC Technical Report 62271-304 "Capacitive current switching capability of air-insulated disconnectors", May 2009.

[11] Y. Chai, P.A.A.F. Wouters, R.T.W.J. van Hoppe, R.P.P. Smeets, D.F. Peelo, "Capacitive current interruption with air-break high voltage disconnectors", IEEE Trans. Power Delivery, to be published.

[12] KEMA test report 411-05, KEMA, Arnhem, the Netherlands, Dec. 2005.

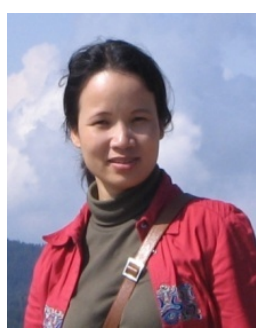

\section{BIOGRAPHIES}

Y. Chai received her M.Sc. degrees from Wuhan University, China in 2001. From 2001 till 2007, she was a lecturer with the Department of Electrical Engineering of Wuhan University. In January 2008, she joined the Electrical Power Systems Group at the Eindhoven University of Technology, Eindhoven, the Netherlands, as a Ph.D. candidate. Her Ph.D. topic is to enhance capability of capacitive current interruption with high-voltage air-break disconnector.

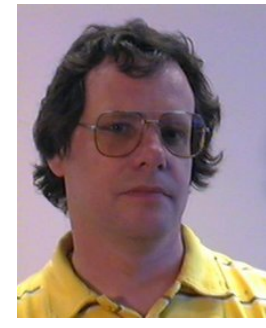

P.A.A.F. Wouters was born in Eindhoven, the Netherlands, on June 9, 1957. He studied physics at the Utrecht University (UU), Utrecht, the Netherlands, until 1984, from which he received the $\mathrm{Ph} . \mathrm{D}$. degree for a study on elementary electronic transitions between metal surfaces and low energetic (multiple) charged ions in 1989. In 1990, he joined the Electrical Power Systems (EPS) group at the Eindhoven University of Technology, Eindhoven, the Netherlands, as Research Associate. His research interests include partial discharge techniques, vacuum insulation, and LF electromagnetic field screening. Currently, he is assistant professor in the field of diagnostic techniques in high-voltage systems.

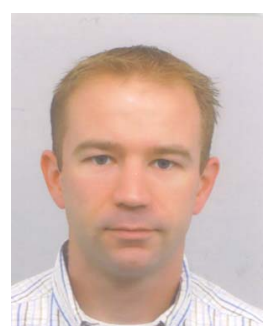

S. Kuivenhoven (1978) obtained his M.Sc. degree in electrical engineering at the Delft University of Technology, the Netherlands in 2004 on the modeling of HV disconnector switching. Since 2004 he is employed at KEMA as specialist in the field of measurement, data analysis, circuit design, and analysis of test-laboratory equipment and shortcircuits generators. He is closely involved in the UHV testing activities at KEMA and in various technology transfer projects in the world regarding high-power testing- and analysis. $\mathrm{He}$ is co-author of several publications on high-power testing.

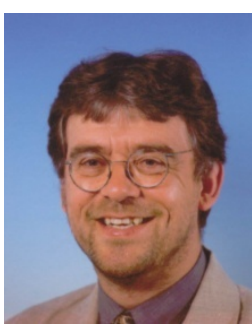

R.P.P. Smeets (1955) received his M.Sc. degree in physics from the Eindhoven University of Technology in 1981. He obtained a Ph.D. degree for research work on switching arcs in 1987. Until 1995, he was an assistant professor at Eindhoven University. During 1991 he worked with Toshiba Corporation's Heavy Apparatus Engineering Laboratory in Japan. In 1995, he joined KEMA T\&D Testing Services. At present, he manages the R\&D activities of KEMA's High Power Laboratory. In 2001, he was appointed part-time professor at the Eindhoven University of Technology. He is/has been chairman and member of various IEC and CIGRE study groups. He is chairman of the "Current Zero Club". He published over 150 papers on high-power switching and testing in international magazines and conference proceedings. In 2008 he was granted an IEEE Fellowship.

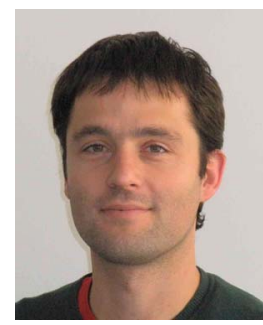

M. Vaniš (1978) received his $M$. Sc. degree in electrical engineering at the Czech Technical University in Prague in 2003 on the studying HV and VHV surge arresters. Since 2003 until 2004 he is employed at HPL ZKU as measuring specialist. Since 2004 he is employed as testing engineer in field of LV, MV and VHV testing and since 2009 is Head of the Control room also. $\mathrm{He}$ is full member of Technical Standards Committee 97 - Power Engineering at the Czech Standards Institute and coauthor of several projects inside the HPL. 